\title{
APLICATIZAÇÃO DA MEMÓRIA: A MEMÓRIA PLÁSTICA DIGITAL
}

\section{CLEYTON CARLOS TORRES ${ }^{1}$}

\author{
Instituto de Estudos da Linguagem, Universidade Estadual de Campinas \\ Cidade Universitária Zeferino Vaz, Campinas, SP
}

ton@blogmidia8.com

\begin{abstract}
Resumo. Este trabalho tem como pressuposto apresentar algumas reflexões e (re)direcionamentos acerca da questão da memória na perspectiva da Análise de Discurso. O trabalho leva como base reflexões levantadas no Projeto CRUA - curtas-metragens de rua, desenvolvido de forma paralela às atividades junto à universidade. É proposto uma reflexão sobre os conceitos de memória discursiva e metálica, sua relação com o uso de smartphones e a relação com o universo digital. Discute-se sobre o conhecimento e a produção de conhecimento pelo funcionamento da memória, sobretudo o que chamamos aqui de aplicatização da memória, como efeito produzido pela memória plástica digital.
\end{abstract}

Palavras-chave: memória; memória metálica; memória plástica digital; aplicatização da memória; memória de smartphone.

\begin{abstract}
This work has as presupposition to present some reflections and (re) directions on the issue of memory in the perspective of Discourse Analysis. The work is based on reflections raised in the CRUA Project - street short films, developed in parallel with activities at the university. It is proposed a reflection on the concepts of discursive and metallic memory, its relation with the use of smartphones and the relation with the digital universe. It discusses knowledge and the production of knowledge through the operation of memory, especially what we call here the application of memory, as an effect produced by digital memory.
\end{abstract}

Keywords: memory; metal memory; digital plastic memory; application of memory; smartphone memory.

A questão da "memória", especialmente às reflexões propostas no Projeto CRUA - curtas-metragens de rua, projeto desenvolvido paralelamente em trabalhos acadêmicos na Universidade Estadual de Campinas (Unicamp) juntamente com a professora Dr ${ }^{\mathrm{a}}$. Cristiane Pereira Dias, tem resultado em muitas inquietações. $\mathrm{O}$ projeto, que visa

\footnotetext{
1 Jornalista e blogueiro. Mestre pelo Laboratório de Estudos Avançados em Jornalismo (Labjor) da Universidade Estadual de Campinas (Unicamp). Pós-graduado em Jornalismo Científico (Unicamp), pósgraduado em Tecnologia, Formação de Professores e Sociedade pela Universidade Federal de Itajubá (UNIFEI). Também possui pós-graduação em Comunicação e História.
} 
"curtografar"2 a cidade com pequenos vídeos de 30 segundos feitos com smartphones, tem o objetivo de produzir movimentos de interpretação do urbano e discutir sobre conhecimento e produção de conhecimento pelo funcionamento da memória. Uma memória do urbano, sobre o urbano, produzida por aqueles que transitam no espaço da cidade. Uma memória que busca o registro e o compartilhamento de si mesma, usando o digital online como meio para se "fazer memória".

O projeto que vem sendo desenvolvido fomentou questões acerca da memória, tanto na concepção tradicional que remetia ao arquivamento mental de dados ou até mesmo lembranças, até inquietações mais agudas que mereciam ser referenciadas e melhor observadas. Entre as inquietações estaria o fato se a memória, ou melhor, o fato registrado via smartphone, seria uma memória do sujeito, mesmo estando armazenada "fora" da mente ou, melhor dizendo, demonstrava ser interessante refletir se essa memória (enquanto registro) "continuada" em outro ponto, armazenada em um aparelho, seria memória, ou se daria da mesma maneira como convencionalmente enquadramos o que em a ser classificado como memória. Mas, de que memória estamos referenciando? É preciso um pouco de conceitualização, antes de mais nada.

Partindo da concepção de que "a memória humana é o acesso a uma notável narrativa, sendo útil na medida em que estabelece relações entre as lembranças e atribui significado às experiências" (SANTOS, 2015, 64), quando recorremos às definições formalizadas - ou institucionais - do que vem a ser o termo "memória", nós nos deparamos com conceitos que trazem similaridades consideravelmente significativas, mesmo em fontes diversas. Para ilustrar, o mecanismo de buscas Google ${ }^{3}$ apresenta, quando o usuário procura por "memória", a faculdade de conservar e lembrar estados de consciência, definição que se assemelha àquela trazida pelo dicionário online Michaelis ${ }^{4}$, que tem como conceito a faculdade de lembrar e conservar ideias, imagens, impressões e conhecimentos. O portal Brasil Escola ${ }^{5}$ diz que memória é o armazenamento de informações e fatos obtidos através de experiências.

É interessante observarmos o uso de termos como "armazenamento", "conservar" e "lembrar". Esses termos também podem ser encontrados na página da Info Escola 6 , que coloca a memória como sendo a capacidade humana de inscrever, conservar e relembrar mentalmente. Podemos notar, aqui, já uma definição voltada para o que seria uma capacidade intrinsicamente humana. Quem contrapõe essa ideia é a enciclopédia colaborativa Wikipédia ${ }^{7}$, que tem como conceito de memória o ato de adquirir, armazenar e recuperar (evocar) informações internas (cérebro) ou externas (dispositivos), ou seja, reafirma a ideia da capacidade humana, mas também joga na mesa uma reflexão sobre

\footnotetext{
2 O termo "curtografar" foi cunhado pelo professor Eduardo Rodrigues, da Universidade do Vale do Sapucaí (Univás), durante participação do autor na II Jornada LinCoTec - Linguagem, Conhecimento e Tecnologia, com a apresentação do trabalho "Projeto CRUA: A produção de conhecimento sobre o urbano a partir da criação de curtas-metragens via smartphones", na mesa temática "Produção de discursos da/sobre a tecnologia no espaço urbano", em agosto de 2016. O termo é em referência ao ato de "curtografar", tal como um verbo, uma analogia em sinônimo ao ato de produzir curtas sobre determinado ponto, sobre algo.

${ }^{3}$ Disponível em https://goo.gl/qYutQg.

${ }^{4}$ Disponível em https://goo.gl/npS62V.

${ }^{5}$ Disponível em https://goo.gl/M6HRqD.

${ }^{6}$ Disponível em https://goo.gl/A5PCWM.

${ }^{7}$ Disponível em https://goo.gl/Ax73A5.
} 
uma memória não humana, não interna, externa, acessível em algum dispositivo. Uma memória, que assim como a linguagem, perderia sua estrutura eminentemente de atividade humana, estendendo-se às máquinas (SCHMITT, 2005), não sendo a memória, ao lado da razão, mais uma potencialidade da interioridade subjetiva, mas como passível de ser projetada em máquinas e, portanto, não subjetivada, dessubjetivada (idem; 2):

com a concepção de máquinas inteligentes, a razão passa a ser uma atividade passível de ser concebida exteriormente ao homem, pois ela é transferida de um suporte biológico a um suporte técnico, o que, segundo Lafontaine (op.cit.), se torna possível pela presença de uma estrutura reprodutível do tratamento da informação: a memória. Esta torna-se, com a cibernética, um dispositivo de estocagem que possibilita as trocas informacionais entre máquinas em interação. (idem)

Uma memória não humana, externa, acessível em um dispositivo outro, mas produzida e referenciada pelo humano, armazenada não de modo aleatório como um algoritmo computacional, mas contextualizada, única. A memória e, desse modo, o conceito amplo que a leva, foi o que se notou com o Projeto CRUA. O armazenamento externo, não humano, daquilo que o humano produz, que acessa posteriormente, compartilha posteriormente, estoca em um dispositivo outro, não biológico, externo.

Com isso, considerando essas definições e conceitos de uma só vez, saltam aos olhos a leitura de memória como sendo algo relacionado, em quase todas as situações, ao acesso e ao armazenamento de algo, geralmente informações, dados, conhecimento ou registros, tópicos que auxiliariam na reinterpretação do passado a partir das problemáticas do presente e também do futuro (SANTOS, 2015). A memória, nas marcações dos locais procurados, sempre reforça essa ideia de acumulação, o não esquecimento, a ativação de movimentos cerebrais intensos ou, até mesmo, a elaboração de meios de se não esquecer ou, ainda, de se esquecer menos, de se forçar a memorizar, trabalhando o ato de decorar como sendo sinônimo de memória. Há, intrinsicamente, um direcionamento ao passado, subjetivo, entrelinhas, pois memorizaríamos algo para o futuro, para que o passado faça sentido em um futuro.

[...] a consciência do passado é uma necessidade humana, avalizada por histórias acerca de pessoas e fatos, comuns à história e à memória. No entanto, o tempo pretérito, nesse exercício consciente, coexiste com a força do presente, ao mesmo tempo em que é distinto dele, quer dizer, a lembrança é guiada pelo sujeito influenciado pelo agora, modificado pelas vivências, mas que precisa olhar para o ontem a fim de organizarse no hoje. (SANTOS, 2015, 65)

Porém, apesar dos conceitos apresentados trazerem semelhanças, a noção de memória é bastante complexa e assume características completamente distintas quando situada em campos teóricos específicos, como é o caso da noção de memória pensada na perspectiva da Análise de Discurso. Desse modo, recorremos aos conceitos de Orlandi (1996) sobre memória metálica, memória discursiva e memória de arquivo para podermos entender um pouco mais sobre essas "diferentes memórias" ou diferentes naturezas de memória, como coloca a autora. 
A memória metálica (ORLANDI, 2006) é aquela que busca entender o funcionamento da memória na relação com as tecnologias de linguagem, trabalhando com a ideia de uma memória que acumula, trabalha com o excesso, a quantidade. É uma memória numérica ( 0 e 1, base do digital), sendo rasa e horizontal. Essa memória tudo acumula, não esquece, atuando com a reprodutibilidade contínua de sentidos, uma memória em eterno continuum. Há estabilização de sentidos e eliminação das diferenças (MENDONÇA, 2004 apud MACHADO, 2015). Nessa memória encontramos um grande palco para o que vemos no universo digital conectado em rede.

Por sua vez a memória discursiva, para a Análise de Discurso, trabalha a relação da memória com a historicidade. $\mathrm{O}$ fato, quando associado a uma série de elementos históricos (conjuntura histórica, por assim dizer), em diferenciadas condições de produção, produz certos sentidos e não outros. Aqui há o esquecimento, diferente da memória de arquivo, que também não esquece (como a metálica), mas de forma normatizada, institucionalizada (há uma institucionalização dos sentidos). Normatiza o não esquecimento, o acesso (ORLANDI, 2006).

Na Figura 1 há um exemplo da relação da memória com a historicidade. As embalagens de pães, na imagem, "conversam" com o cliente, sussurrando "sou rico em fibras" ou "tenho menos sódio". A relação da memória com a historicidade resulta na construção dos sentidos, remetendo a um acionar da memória relacionado a algo saudável, menos prejudicial à saúde, historicamente inserido. Uma ação de marketing, afirmariam alguns especialistas em comunicação mercadológica, mas que trabalha com a ideia de memória na relação com a historicidade.

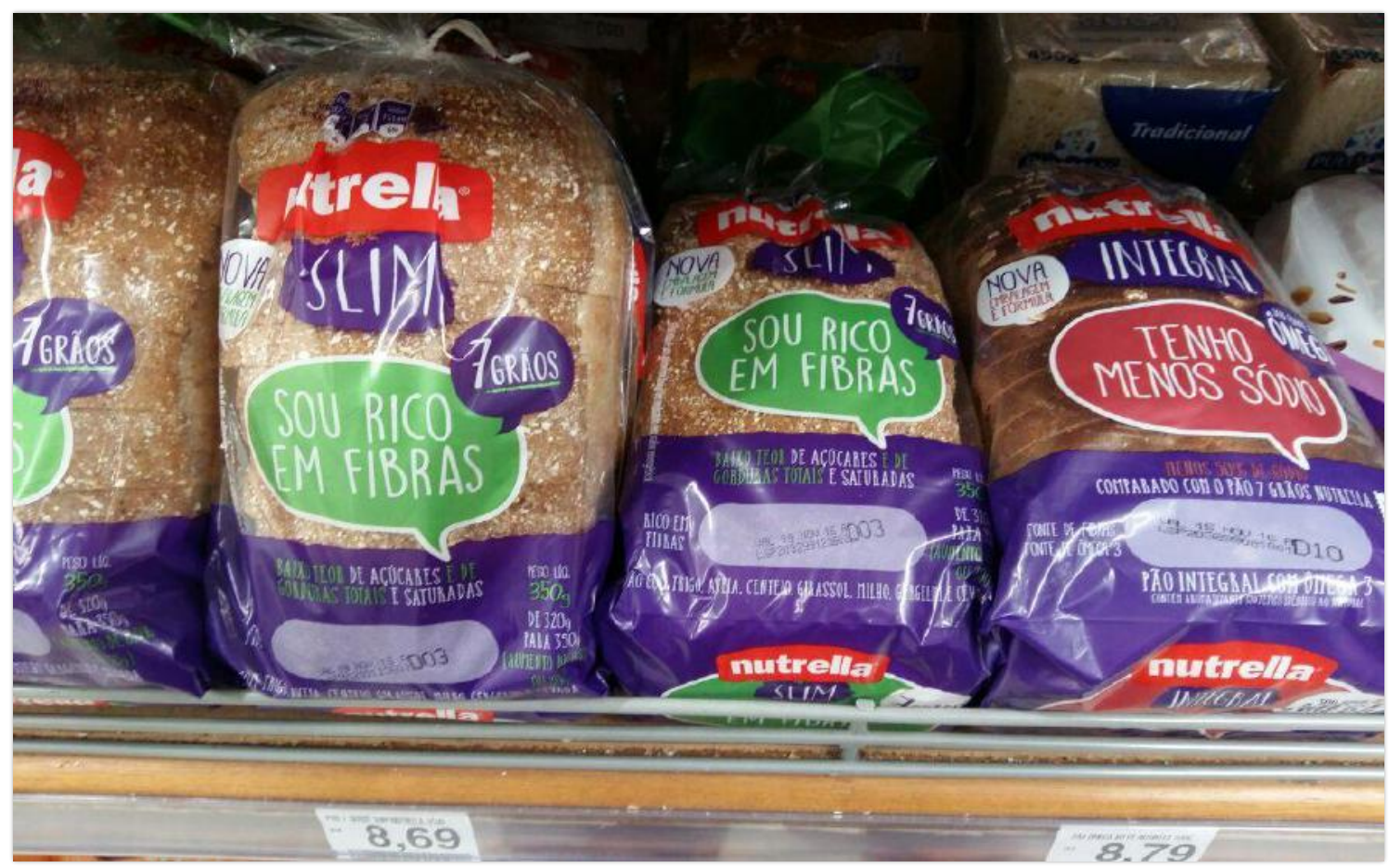

Figura 1 - Pães com "diálogos". Foto de arquivo pessoal. 
Desse modo, podemos trazer para esse texto tantos outros "meios" de memória que nos interessam, indo além do exposto da figura 1 , já remetendo para a relação da memória com o digital, como um disco rígido de um computador, local próprio para o depositário de dados do usuário (sem contar que também temos, quando falamos em computador, a memória ram). Há também a memória portátil, ou pendrives e os chamados cartões de "memória", seja para máquinas fotográficas, celulares ou tablets. Temos as memórias da e na nuvem, quando associamos a capacidade de se armazenar dados digitais em serviços que usam como base centros de processamento espalhados pelo mundo, os data centers, formulando uma memória cloud.

Entretanto, uma "memória" tem sido mais particularmente trabalhada nos últimos tempos, e que é o nosso canal de reflexão no Projeto CRUA. A "memória de smartphone", uma memória que é produzida por um smartphone e só deve ser acessada por um smartphone - sendo assim, (re) produzida. É uma memória que só "existe" se registrada com tais aparelhos. Os usuários repassam um movimento que nos perpassa a ideia de que os registros de experiências como um show musical, um evento esportivo, uma manifestação contra a corrupção do governo ou os primeiros passos do filho só serão, de fato, armazenados, conservados e arquivados se forem gravados ou fotografados com um smartphone para, em seguida, só poderem ser acessados por um smartphone. Acrescenta-se, aí, uma "memória" que é facilmente compartilhada para com outros usuários de smartphones. Uma memória que acumula e não necessariamente interpreta, metálica, deixando o usuário imerso em um eterno presente, já que há o registro e sua reprodução dentro de um movimento de aparência ilimitada, sem limites ${ }^{8}$, criando-se uma nova lógica do instante que elimina do nosso horizonte tanto o passado quanto o futuro, eliminando a historicidade (ROBIN, 2016).

Vivemos sob o domínio do imediato, do efêmero, do instante, do clique, do salto, da ubiquidade, sob o domínio do tempo real em que o que se está se efetuando e sua representação se confundem, sem falha, sem distorção temporal, em um eterno presente que, como tal, tem a tendência a ignorar o passado, a anterioridade, e não se preocupar com o futuro como uma reiteração do presente. (idem; 401)

De uma compreensão inicial que pode ser feita quanto ao funcionamento dessa "memória de smartphone", temos como base o que estamos aqui chamando de uma aplicatização da memória, uma memória que, para ser funcional, necessita de certos elementos:

- Device: um dispositivo para funcionar;

- Social: contexto social entre usuários;

- Digital: precisa ter plataforma digital;

- Conectado: o acesso à uma rede é um dos itens essenciais;

- Em rede: a conexão deve ser em rede, com todos os nós;

- Acúmulo: o processo de acumulação de conteúdo, sobretudo na nuvem;

\footnotetext{
8 Conceitua-se, aqui, uma "aparência sem limites" ou "ilimitada" a sensação de infinitude trazida, sobretudo, pelo universo digital online. De fato, e fisicamente falando, o online não é infinito, já que trabalha com base em largura de bandas e data centers espalhados pelo mundo, o que inviabilizada, literalmente, quando trabalhada, a ideia de infinito. Porém reconhece-se que essa "aparência sem limites" é estabelecida como normativa dentro do pensamento daqueles que acesso o digital online, sobretudo via smartphones.
} 
- Editável: uma memória que é editável e modificável;

- Compartilhável: uma memória que pode ser "enviada" para outra pessoa.

A aplicatização da memória dispõe uma "memória" com facilidade de acesso, bastando apenas um dispositivo, como um smartphone, e oferece várias formas para esse acesso, seja por meio de busca, itens relacionados ou até mesmo por voz. É uma memória com opção de busca. A velocidade também chama a atenção, já que com apenas um toque o usuário pode acessar uma "memória" desta manhã ou de 10 anos atrás, sendo seu acesso e seu acúmulo frenéticos e instantâneos. Uma forma de se praticar uma memória que mexe com a "velocidade dos sentidos" (DIAS, 2013), por assim dizer, já que a noção de tempo, ressignificada, deslocada, muda a "forma das relações sociais, a linguagem e a escrita" (idem, 63) - e, porque não, da memória. A aplicatização da memória elimina a temporalidade e torna o espaço obsoleto (ROBIN, 2016), substituindo o tempo pelo espaço (idem), colocando o mundo em um presente eterno, onde o "indivíduo vive no instantâneo da comunicação e na ubiquidade de estar em todos os lugares ao mesmo tempo" (idem; 410).

Mais dia, mais noite, mais espaço, mais tempo, um ciberespaço abstrato no qual reina uma atemporalidade que se pode chamar de eterno presente. Sociedade da comunicação e da informação, porque a qualquer momento, graças aos múltiplos bancos de dados que estão à minha disposição, eu posso dispor de uma gigantesca quantidade de informação sobre qualquer assunto. (ROBIN, 2016, 403)

A ideia de aplicatização da memória, fato referenciado aqui pelo Projeto CRUA, é uma memória que atravessa os conceitos de memória, desloca-os, misturando significados e definições. Metálica, discursiva, de arquivo, registro, armazenamento, dados, fatos, acesso, memória como lembrete, memória como não esquecimento ou menos esquecimento, memória decorada, memória profunda, rasa, compartilhável. A aplicatização da memória, quando começou a nos inquietar, trouxe todos esses tópicos de uma vez. É uma memória elástica, externa, removível e acessível. Uma memória "terceirizada", mas em primeira pessoa.

O conceito que chamamos de aplicatização da memória traz, também, limites, pois exige que seu registro e seu acesso sejam realizados por um dispositivo, resultando em uma memória em pílulas, não contextual, não profunda, rasa e superficial. Uma memória que funciona na cooperação entre máquina e homem, "através do desenvolvimento de linguagens que permitam a produção de conteúdos legíveis tanto para/pelo usuário quanto para/pela máquina" (DIAS, 2013, p. 59), tal como uma memória híbrida homem-máquina. Através de "fragmentários do eu" (idem, p. 67) o sujeito se constitui, mesmo que através de banalidades, com a necessidade de fixar (idem) - pela memória. A memória de smartphone funciona com segmentação, de forma fragmentada, conectada e articulada em rede.

A aplicatização da memória tem como base uma hibridização de "plataformas", a humana (mental) e a não humana (digital). Ao se trabalhar com essa hibridização de duas frentes, o usuário de smartphone "reorganiza" a memória via aplicativo, conforme o que um determinado aplicativo oferece como recurso (fotos, vídeos, lembretes de reuniões), fazendo com que o usuário estabeleça uma nova relação com a "memória", modificando profundamente como o sujeito se relaciona com a memória via/de aplicativo, 
modificando, inclusive, a forma como ele se constrói. É a representação matemática da memória. A memória produzida pelo sujeito com um smartphone continua de outro jeito, de outra maneira, no externo, no que será acessado e compartilhado depois, distorcida pela tecnologia. É uma memória multi, multimemória, uma transmemória que passa na hibridação homem-máquina.

É possível ilustrar essa representação matemática da memória na previsão do tempo indicada pelo smartphone ou pelo caminho indicado por aplicativos de trânsito. Não mais necessito saber se irá chover e não mais preciso saber como chego até a casa de meus pais, pois a aplicatizaçaão da memória torna tudo palpável, a dedos. Com poucos toques sou "lembrado" para me proteger dos dias chuvosos, como ilustrado na figura 2, onde a rede social Facebook, sem mesmo que eu requisite, notifica o usuário para dias chuvosos. Com poucos toques registro o destino que preciso chegar, sem ao menos precisar saber o nome da rua, já que muitos aplicativos permitem o envio de localização de forma direta, sem a necessidade de inserção de dados do endereço a ser acessado. Lembro da casa de meus pais e do caminho, mas a memória de como chegar até lá é distorcida pela tecnologia e continuada, de um jeito outro, no digital.

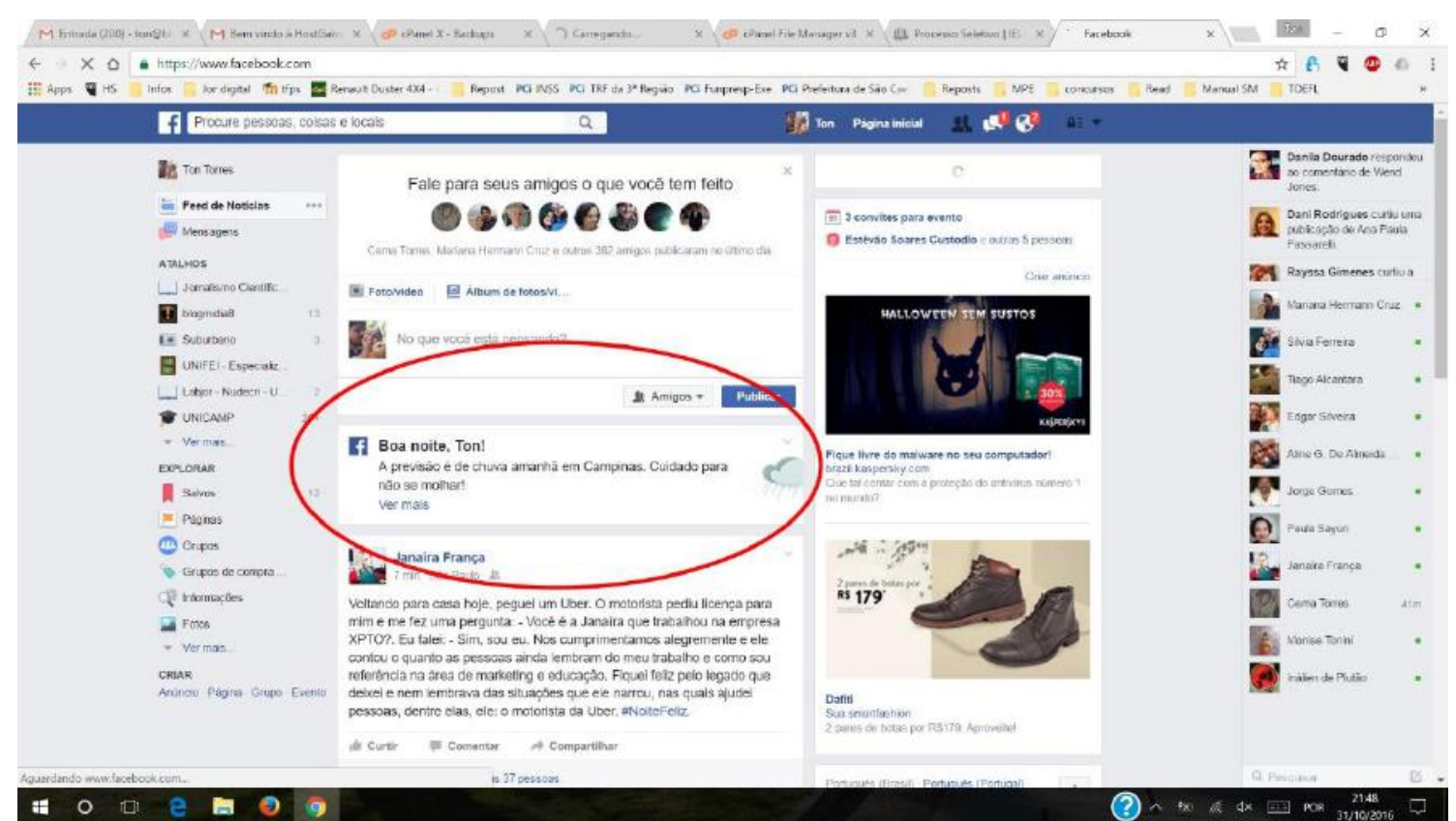

Figura 2 - Captura de tela da rede social Facebook. Com pouco toques o usuário é "lembrado" sobre dias chuvosos e alertado para que não se molhe.

Em outras exemplificações é possível observar como a relação do sujeito é deslocada com a transmemória, com essa aplicatização da memória, já que atravessa os significados de saber, decorar, registrar ou lembrar e entrega um efeito outro produzido pela memória plástica digital. Na figura 3 temos capturas de telas do aplicativo Up! Plasútil, desenvolvido por uma empresa de recipientes plásticos que trabalha com a ideia de "memorização", como apresentado pelo recurso, que auxiliaria determinado sujeito munido de seu smartphone a recordar tudo o que foi inserido e armazenado em cada recipiente ou pacote. Não mais necessito utilizar apenas minha memória biológica para recortar onde armazenei cada alimento, pois a aplicatização da memória permite que eu 
exteriorize isso, amazene em um local outro ou, ainda, delegue tal função a uma memória externa, digital, acessível via aparelho de celular. O aplicativo demostra o que foi inserido em potes ou pacotes, com catalogação.

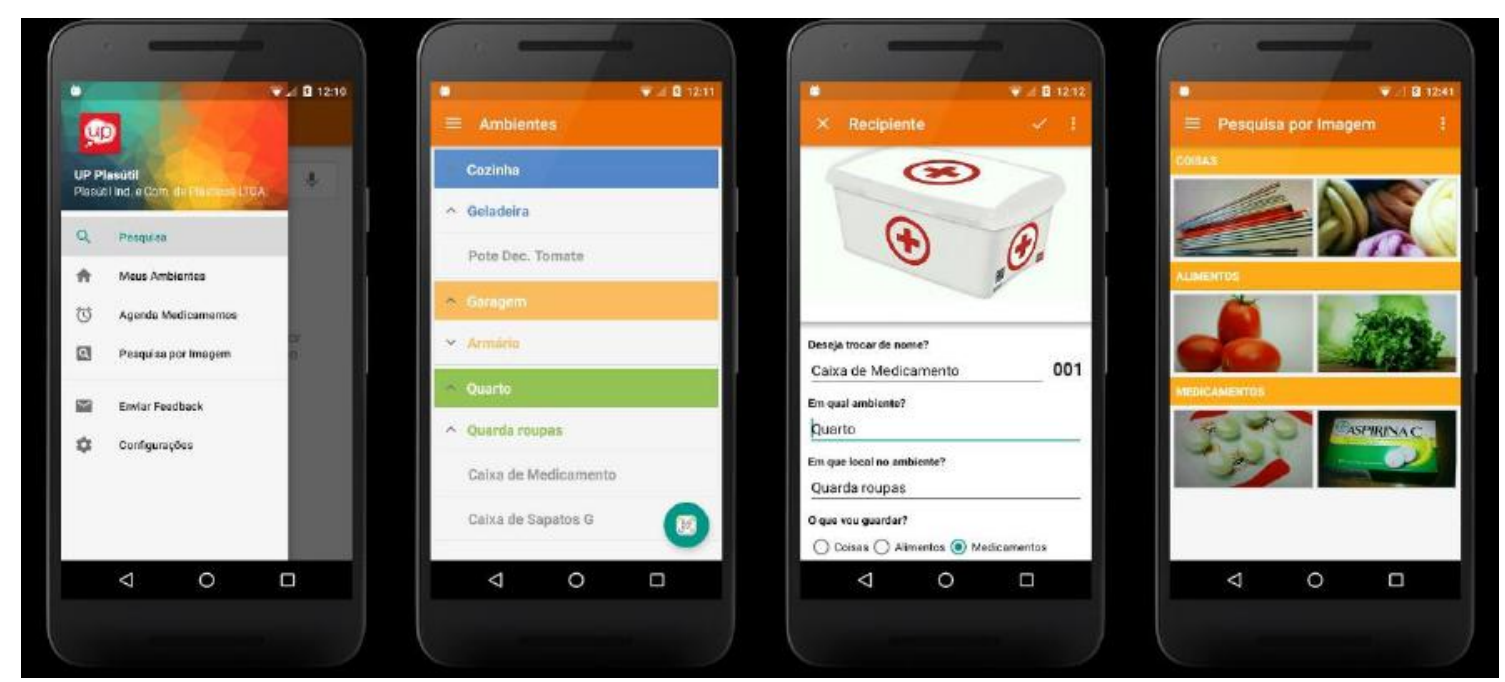

Figura 1 - Up! Plasútil é um aplicativo para smartphone que promete ajudar na "memorização" do que foi inserido em potes e pacotes, com catalogação. Disponível em https://goo.gl/8LqYSu.

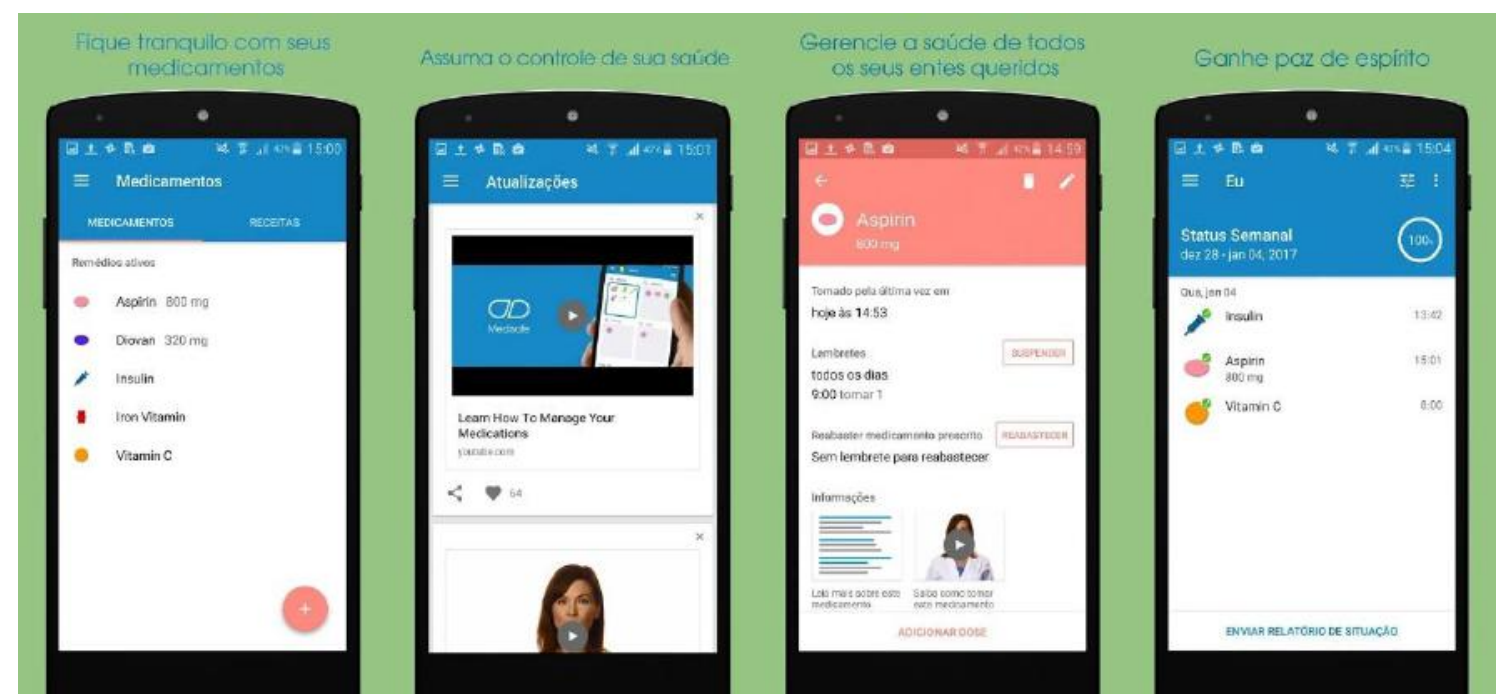

Figura 2 - Aplicativo Medisafe demonstra como a relação do sujeito é modificada. A ferramenta oferece recursos para que você "memorize" quais remédios deve tomar, inclusive o horário e a dosagem correta.

Disponível em https://goo.gl/PP4RLf.

Em outro recorte ainda mais específico pode-se observar que é possível projetar até mesmo itens mais importantes do dia a dia, como os cuidados com a nossa saúde, para dispositivos externos, memórias externas. A figura 4 traz capturas de telas de um aplicativo denominado Medisafe, que tem como principal recurso oferecer a "memorização" de quais remédios tomar, quando e em que dosagem. O fato de deixar que o cuidado com a própria saúde seja "gerenciado" por um aplicativo expõe como a memória é distorcida (reestruturada) pela tecnologia e continuada em um local outro. Temos, aqui, noções que poderíamos remeter aos conceitos de memória como registro, 
no senso comum, mas também às memórias metálicas, discursiva e de arquivo, conceitos expostos de forma atravessada, onde os sentidos são construídos justamente nessa travessia.

Mesmo que o fato não seja mais possível de ser acessado, que não seja possível acessar o passado de modo "verificável objetivamente pelo ato de observar ou experimentar" (SANTOS, 2015, 66), o ato de registrar, do registro, remete à "possibilidade da existência de um tempo pretérito (idem). No coletivo do compartilhamento, na elaboração desse imenso banco de dados com "memórias", ao acessá-lo, o sujeito (re) estrutura suas próprias memórias com base na memória do coletivo, onde há uma imbricação acentuada de qual memória "é sua" e qual ele nunca viveu e experimentou. A memória do outro, lançada na rede, (re) constrói sua memória, pois usamos memórias externas para resolver lapsos internos. O coletivo de memórias individuais, quando na rede, reconfiguram as memórias individuais quando acessadas em/na rede. A memória do coletivo, ou se falarmos em dados, o Big Data, é uma memória construída virtualmente (em duplo sentido), uma espécie de metamemória conectando uma "humanidade digital".

A aplicatização da memória permite que o sujeito se projete, se escreva e se inscreva. A memória de smartphone é uma forma do sujeito se experimentar no digital, mesmo que haja o "esvaziamento do sentido dos acontecimentos" (DIAS, 2013, p. 59), já que tudo é publicado na rede "produzindo aos acontecimentos sentidos do efêmero da circulação da informação" (idem). No processo de mediação da memória há perdas e ganhos, amplificações e reduções. Há uma automutação, a memória é continuada além corpo físico, ela continua de outro jeito, de outra maneira. Há um alongamento da percepção de memória, de registro, uma presença (virtual) de memória. É significada conforme é registrada, conforme circula e é acessada. O sujeito memoriza, significa e é significado enquanto pratica a memória de smartphone. É uma transmemória, uma memória que distorce e é distorcida pela tecnologia, reestruturada pela tecnologia. Conforme o grau de usabilidade do sujeito com as tecnologias digitais e móveis varia sua relação com a aplicatização da memória.

\section{Considerações finais}

A aplicatização da memória trabalha com uma memória simulada, um simulacro. O registro desenfreado de tudo e todos através não de olhos e experiências, mas cliques e telas de smartphones, coloca o usuário em uma não vivência, uma não experiência daquilo que está diante dele. Há uma simulação de que o sujeito viveu tal momento apenas pelo fato do mesmo ter registrado o evento no dispositivo. $\mathrm{O}$ acesso, mais tarde, também via dispositivo, assim como a edição dessa memória e seu compartilhamento, complementam a simulação de que uma memória está ativa, viva, "memorizada". A memória de smartphone trabalharia com uma sequência associativa, com segmentação, de forma segmentada, articulada, conectada, tendo como base uma espécie de nó entre o sujeito e o digital.

A memória no digital, uma memória plástica digital, seria parte do "reino da falsificação de dados" (ROBIN, 2016, p. 412). Como tudo é digitalizável (imagem, texto, 
som, vídeo) tudo poderia ser manipulável (idem), onde "não só não poderíamos mais distinguir as imagens 'reais' das imagens em síntese ou de "realidade aumentada" (idem), ou memórias "reais" das memórias de outros, do coletivo, das quais tomamos para que possamos nos (re) construir. A aplicatização da memória, com a ideia de reflexão proposta trazida para este artigo, trabalha com uma dimensão temporal gerenciável, obscura na divisão entre lúdico e virtual, uma memória líquida, híbrida, que traz para a conversa muito mais interrogações que afirmações. Esta aí, acessível, editada, compartilhada, mas é minha, está aqui em meu dispositivo.

Por fim, as inquietações que propusemos a refletir um pouco nesse artigo oferecem campos a serem explorados com mais profundidade. A aplicaticação da memória, efeito que modifica nossa relação com a memória, nos oferece essa tenda de simulacro. Ao desligar a tela do aparelho, voltamos, alterados, porém, às nossas memórias em paralelo com as memórias que nos foram compartilhadas artificial e virtualmente. Programamos e somos programados no que tange a memória, assim como o arame com memória, uma substância chamada Nitinol que possui "memória", sendo capaz de ser "programada" para quando sofrer alguma alteração física (uma deformação, por exemplo), possa voltar à posição de origem quando exposta a uma determinada temperatura (quente ou fria, já pré-programada), retornando ao formato de origem, ao formato que estava em sua "memória".

O deslocamento da relação do sujeito com a memória, a memória continuada em um lugar outro e a memória reestruturada, modificada pela tecnologia, são os principais pontos que pudemos levantar com o desenvolvimento do Projeto CRUA, ainda em curso, o que resulta em observações voláteis, em movimento, em constantes deslocamentos.

\section{Referências}

DIAS, C. A poética do cotidiano na rede. Signo y Seña, n. 24, 57-70, 2013. Facultad de Filosofía y Letras (UBA). Disponível em http://revistas.filo.uba.ar/index.php/sys/index.

A discursividade da rede (de sentidos): a sala de bate-papo HIV. Tese. Doutorado em Linguística, Universidade Estadual de Campinas, 2004.

ORLANDI, E. Análise de Discurso: Conversa com Eni Orlandi. Teias, 7, 13-14, Rio de Janeiro, 2006.

Interpretação: autoria, leitura e efeitos do trabalho simbólico. Rio de Janeiro: Vozes, 1996.

MACHADO, F. Memória discursiva, do metal à memória: a perspectiva da AD francesa no Brasil, 2015. Disponível em http://dcdigital.hypotheses.org/253.

ROBIN, R. A memória saturada. Trad. Bras. Campinas: Editora da Unicamp, 2016. 
SANTOS, R. Os labirintos da memória, da história e da representação do sujeito feminino em El Dock, de Matilde Sánchez. Signo, Santa Cruz do Sul, v. 40, n. 69, 64-70, jul./dez. 2015.

SCHMITT, M. Sobre uma memória sem sujeito? Seminário de Estudos em Análise do Discurso [Anais], 2, Porto Alegre, 2005. Disponível em http://www.analisedodiscurso.ufrgs.br/anaisdosead/sead2.html. 2005.

Artigo recebido em: julho de 2017.

Aprovado e revisado em: outubro de 2017.

Publicado em: novembro de 2017.

\section{Para citar este texto:}

SILVA, Cleyton Carlos Torres Ferreira da. Aplicatização da memória: a memória plástica digital. Entremeios [Revista de Estudos do Discurso, on-line, www.entremeios.inf.br], Seção Temática [Linguagem e Tecnologia], Programa de Pós-Graduação em Ciências da Linguagem (PPGCL), Universidade do Vale do Sapucaí (UNIVÁS), Pouso Alegre (MG), vol. 15, p. 357-367, jul. - dez. 2017.

DOI: http://dx.doi.org/10.20337/ISSN2179-3514revistaENTREMEIOSvol15pagina357a367 